\title{
The Green Sustainable Economic Development Model under Sustainable Use of Energy and Pollution Control*
}

\author{
Wanping Yang ${ }^{1,2}$, Lan Ban ${ }^{1}$ \\ ${ }^{1}$ School of Economics and Finance, Xi'an Jiaotong University, Xi' an, China \\ ${ }^{2}$ School of Public Policy Administration, Xi'an Jiaotong University, Xi'an, China \\ Email: wanpingyang@mail.xjtu.edu.cn, banlan.2007@stu.xjtu.edu.cn
}

Received November 22, 2012; revised December 23, 2012; accepted January 25, 2013

\begin{abstract}
As concerns about energy and environment emerge the concept of sustainable development, this paper develops a five-sector endogenous technological change economic growth model considering sustainable use of energy and pollution control. We introduce energy and environment into production function and utility function, solve the conditions for sustainable economic growth with the optimal control method, further reveal the dynamic relationship which should be met by energy consumption rate, pollution control and sustainable economic growth, prove the possibility of sustainable economic growth and reveal the path and conditions of sustainable economic growth under the dual constraints of energy and environment.
\end{abstract}

Keywords: Sustainable Use of Energy; Pollution Control; Sustainable Economic Growth

\section{Introduction}

In the past 30 years, China has experienced a sustainable and rapid economic growth, which is partly stimulated by the extensive mode of economic growth aimed to GDP one-sided. However, a series of problems such as energy shortage and environmental pollution has been brought meanwhile. Faced with a "dilemma" between energy and development in the traditional sense to a "tripartite tangle" of energy, environment and development, the state proposed the strategic goal of building a "twooriented society" timely, trying to achieve the harmony and unity of the three by integrating. Based on these above, this paper intends to introduce energy consumption and environmental pollution into production function and utility function as independent factors in order to explore the possibility and conditions of sustainable economic growth under the dual constraints of energy and environment.

\footnotetext{
"Supported by: the major project of State Social Sciences Fund: countermeasures study of the transformation of economic development in China to promote scientific development (11AZD001); the Program for New Century Excellent Talents in University of Ministry of Education of China: the research on the index evaluation system of Chinese low-carbon economy (NCET-10-0683); the youth programs of State Social Sciences Fund: energy consumption, pollution emissions and sustainable economic development in China (10CJL034); China's Postdoctoral Fund: the transformation and sustainability of economic development in China in "tripartite tangle" society (2012M521752).
}

\section{Literature Review}

In 1980s, economists, such as, Romer [1,2] and Lucas [3], explain the source of a country's economic growth by endogenous economic growth model, which has attracted widely attention from scholars. As endogenous economic growth model gets rid of the shackle that long-term growth is pinned on by exogenous technological progress in the neoclassical model, it is possible to analyze longterm economic growth. Therefore, it is possible to introduce energy resources, environmental pollution, etc. into production function or utility function as endogenous elements, thus scholars can discuss energy depletion, environmental pollution and sustainable economic development issues in the framework of endogenous economic growth model.

Some research introduces non-renewable resources into endogenous model to study the impact of energy resources depletion on long-run economic growth, such as Shui-jun Peng [4] and Shi-chun Xu, etc. [5]; others introduce environmental quality or pollution into production function to analyze the relationship between environmental quality and economic growth in the framework of endogenous growth model, for example, Li Shibing, Ding-tao Zhao [6] and Jing Huang [7]; moreover, Bin Zhang, Hui Zuo [8] Shi-chun Xu, etc. [9] go further, they introduce both energy and environment into endogenous economic growth model to describe necessary 
conditions for sustainable economic growth more comprehensively. However, there are still the following shortcomings in the informed research: 1) Most of them are only based on energy depletion. Obviously, leaving the impact of renewable energy on the energy stock out of consideration is not only unscientific but also inconsistent with the fact that the world is vigorously developing renewable energy; 2) Although the research of Zhang Bin and Zuo Hui [8] introduce Lucas endogenous growth model to consider the impact of renewable resources, they don't explain mechanism of technology on energy stock sufficiently, thus energy endogenous is lack of a adequate basis. Therefore, in terms of research significance, the research doesn't combine the essences and internal logic of endogenous growth model with the constraints of energy depletion on economy. In fact, in the light of the internal logic of endogenous growth model, it is endogenous technology that solves the scale descending of other factors (including energy and environment) to make sustainable economic growth possible; 3) For easy figures, most papers suppose human capital equals labor force in the production function. However, whether from realistic perspective or theoretic importance, human capital and labor force can't be completely interchangeable; 4) Most don't consider the impact of environmental protection investment on pollution emissions, in their model there is only one control variate-technical level to represent the correlativity between pollution emissions and outputs suggesting investment only has a negative effect on environmental system and ignoring the positive effect of environmental protection investment. Actually, environmental protection investment contributes a lot to improving environmental quality; 5) Even though some of them introduce both energy and environment into endogenous economic growth model, into only production function but no utility function, which does not fit with the objective that people pursue maximizing social welfare under the dual constraints of energy and environment.

In view of these, this paper attempts to expand research in the following aspects: 1) we introduce energy endogenous into production function, when characterizing energy factor we take full account of both exhaustible non-renewable resources and renewable resources to meet the fact that the world is vigorously developing renewable energy; 2) We introduce the negative effect of environmental pollution on economy into production function as an independent factor; 3) Owing to the importance of human capital, we discriminate between labor force and human capital, which is not only consistent with the original intention of Romer endogenous growth but also closer to the nature of things; 4) We take the contribution of environmental protection investment to environmental quality into account and introduce the positive effect of environmental protection investment on environment into the analytical framework; 5) We adopt an additive and isoelastic social welfare function includeing both energy consumption and pollution stock, which can combine endogenous growth theory and sustainable development specification.

\section{Model Specification}

\subsection{Framework of Endogenous Technological Change Model}

In the process of model specification, we consider five types of departments: finished product department, intermediate product department, R \& D department, energy development department and environmental pollution control department. For purpose of analysis, we leave out the growth of population and standardize the total population in economy $\mathrm{L}$ into $1(L=1)$, thus all the total variable can be regarded as per capita variable. Suppose in economy the supply of human capital $H$ is inelastic and a fixed number in total, the distribution of human capital between finished department and R \& D department is endogenous and fixed, the amount of human capital in finished department and R \& D department are $u H$ and $(1-u) H$.

\subsection{Production Technology}

R \& D department: The R \& D department uses only human capital and the pre-existing knowledge stock $N$ to product new knowledge or new intermediate product design. As knowledge is constantly updated and ageing at the same time, we introduce the parameter about technology ageing in Karl Shell model [10] into the knowledge accumulation equation, then the equation of changes in the per capita technical knowledge is:

$\dot{N}=\pi(1-u) H N-\sigma N, \pi \succ 0$. In the formula: $\dot{N}$ is the increases of per capita technical knowledge; $\pi$ is the productivity parameter of $\mathrm{R} \& \mathrm{D}$ department; $(1-u) H$ is the total amount of human capital in R\&D department; $N$ is the stock of pre-existing knowledge; $\sigma(\sigma \succ 0)$ is the aging rate of knowledge. Obviously,

$\dot{N} / N=\pi(1-u) H-\sigma$, owing to $H \succ 0$, provided the production speed of knowledge exceeds the aging speed of it, namely $\pi(1-u) H-\sigma \succ 0$, the accumulation of knowledge can be unlimited. It not only indicates the significance of valuing science and technology studies as well as increasing the human capital in scientific research department, but also shows the importance of scientific and technical innovation.

Intermediate product department: Intermediate product department uses the new product design $N$ and material capital $K$ to product intermediate products $X$. Like the research of Barro etc. [11], assume once a new product variety or design has been invented by R \& D department, 
producing a unit of any one type of intermediate product $x(i)$ just consumes a unit of material capital $K$, thus the total amount of the per capita material capital in

economy is: $K=\int_{0}^{N} x(i) \mathrm{d} i=N X$. In the formula: $K$ is the total amount of per capita material capital; $X$ is the production of per capita intermediate products.

Finished product department: We introduce both energy and pollution into production function, suppose both energy input $E$ and pollution stock $P$ are the essential conditions for outputs $Y$, thus the per capita output in economy $Y$ depends on intermediate inputs $X$, labor $L$, human capital $u H$, energy factor $E$ and pollution stock $P$ used by finished product department. Production function adopts the $\mathrm{CD}$ form, in the assumption that the population of labor force is the constant 1, the production function of per capita output $Y$ is Formula (1):

$$
\begin{aligned}
Y & =u^{\alpha} H^{\alpha} E^{\beta} P^{-\theta} \int_{0}^{N} x(i)^{1-\alpha-\beta} \mathrm{d} i \\
& =u^{\alpha} H^{\alpha} E^{\beta} P^{-\theta} N X^{1-\alpha-\beta} \\
& =u^{\alpha} H^{\alpha} E^{\beta} P^{-\theta} N^{\alpha+\beta} K^{1-\alpha-\beta}
\end{aligned}
$$

and, $(0 \prec \alpha, \beta, 1-\alpha-\beta \prec 1, \theta \succ 1)$.

Capital stock: The production of material capital can be used in three departments: 1) consumer $C$; 2) the current investment $K$, which directly increases the stock of physical capital; 3) pollution protection $V$ to improve the environmental quality and reduce the stock of pollutants. As the depreciation of material capital doesn't influence the growth rate on the balanced path, we leave out it. Thus the equation of changes in the per capita material capital is: $\dot{K}=Y-C-V$. And, $\dot{K}$ is the rate of changes in per capita material capital, namely the variation of per capita material capital in unit time; $C$ is consumer; $V$ is environmental protection investment. For simplicity, suppose the relation between environmental protection investment and capital stock is: $V=\phi K \quad(0 \prec \phi \prec 1)$, and $\phi$ is the proportion of environmental protection investment in capital stock. Thus, $\dot{K}=Y-C-\phi K$.

Energy constraints: Decision-makers must put a certain amount of energy into production to achieve sustainable economic growth, so the productivity of energy should meet the energy needs for economic growth. In this paper, $S$ represents the per capita energy stock, which contains two different types of energy, one is renewable resources and the other is non-renewable resources. Technical change impacts on the energy stock through the following three ways: 1) exploring the potential non-renewable resources by exploration technology; 2) improving the efficiency of exploitation and intermediate link via the exploitation and development technique; 3 ) improving the utilize efficiency of energy in the production process. In the long run, technical change makes energy stock increase and is the fundamental way out for ensuring the increase of energy stock, thereby, research conclusions of the relation between energy constraints and sustainable economic growth become more scientific and also more truthful [12]. Assume technical change makes the per capita energy stock $S$ maintain a certain rate of natural growth via three mechanisms above, which is named $\eta$, a constant greater than zero, and the input of energy is $E$, thus the equation of changes in per capita energy stock $S$ is: $\dot{S}=\eta S-E$. And, $\dot{S}$ is the rate of changes in per capita energy stock; the constant $\eta \succ 0$.

Environmental constraints: So as to introduce environmental constraints into endogenous growth model, we assume that environmental quality $P$ is influenced by two aspects: one is the self-purification capacity to pollutants in environmental system; the other is the impact of human production activities on environment. Accordingly, the equation of changes in per capita pollution stock is: $\dot{P}=\varphi^{-b} K^{-b} Y N^{-a}-\varpi P$. In the formula: $\dot{P}$ is the rate of changes in per capita pollution stock; $a$ is the clean index of energy technology and greater than $1 ; \varpi(0 \prec \varpi \prec 1)$ is a constant which means the self-purification capacity to pollutants in environmental system; $\varpi P$ indicates the attenuation proportion of pollution stock at any one time remains unchanged, the linear hypothesis is completely for easy figures; suppose $P^{\max }$ is the threshold of environmental capacity, from the angle of sustainable development, at any one time pollution stock must satisfy: $P \prec P^{\max } ; N^{-a}$ is equivalent to $Z$ in Stokey model [13], however, it is no longer separate from production system and pollution control; $Y N^{-a}$ is the current pollution stock caused by production activities, which is proportional to the current economic output $Y$ and inversely proportional to the level of energy technology $N$; $\phi^{-b} K^{-b}$ is the contribution of environmental protection investment to environmental quality, and $b(1 \succ b \succ 0)$ can be seen as investment efficiency of environmental protection, which indicates environmental quality can be improved by stably increases of environmental protection investment and the contribution of technology to environmental quality includes not only reducing the pollution produced by output but also the positive effect of enhancing the investment efficiency $b$. Thus, the economic output produces environmental pollution, both environmental protection investment and environmental self-purification capacity improve environmental quality, while technological progress reduces pollution and enhance the investment efficiency $b$, environmental protecttion investment, technology and environmental quality are taken as an endogenous whole [8]. By virtue of variables $Y, \phi, N$, the equation of changes makes energy use and pollution control costs endogenous at the same time, then energy use $E$ (through $Y$ ), investment in pollution control (through $\phi$ ) and technology evolution $N$ systematically form a dynamic system, thereby, the endogenous 
process of variables is finished.

Utility and target function: We build an additive and isoelastic social utility function based on consumer, energy resources and environmental quality to combine endogenous growth theory and sustainable development specification:

$$
\begin{aligned}
U(C, S, P)= & \frac{C^{1-\varepsilon}-1}{1-\varepsilon} \\
& +\frac{S^{1-\omega}-1}{1-\omega}+\frac{P^{1+\varphi}-1}{1+\varphi}
\end{aligned}
$$

In the formula: $U$ is instantaneous utility function; $S$ is the per capita energy resources stock at time $t$ (including exhaustible resources and renewable resources); $P$ is the per capita pollution stock of environment at time $t$; $\varepsilon, \omega, \varphi(\varepsilon, \omega, \varphi \succ 0)$ are the reciprocal of the intertermporal elasticity of substitution for consumption and energy as well as pollutants, all of them are larger than zero.

Assume there is a rational social planner, the target and task of optimization model are to maximize the present value of social utility of the current and coming generations, that is, under the constraints of capital, energy and environment, to maximize intertemporal utility through the choice of appropriate path. Build a dynamic model simultaneously considering energy resources, environmental pollution and pollution control in the condition for continuous time, thus the target of the rational social planner is translated into the problem of solving the dynamic optimization model. Suppose $\rho$ is the discount rate of intertemporal utility, the total social utility discounted for an infinite time horizon is

$$
\int_{0}^{\infty} U(C, S, P) \mathrm{e}^{-\rho t} \mathrm{~d} t
$$

so the rational social planner can build target function as follows, namely, a integrated endogenous economic growth model which considers sustainable use of energy, pollution control and sustainable economic development:

$$
\begin{aligned}
& \max U(C, S, P)=\max \int_{0}^{\infty} U(C, S, P) \mathrm{e}^{-\rho t} \mathrm{~d} t \\
& =\max \int_{0}^{\infty} \mathrm{e}^{-\rho t}\left(\frac{C^{1-\varepsilon}-1}{1-\varepsilon}+\frac{S^{1-\omega}-1}{1-\omega}-\frac{P^{1+\varphi}-1}{1+\varphi}\right) \mathrm{d} t
\end{aligned}
$$

In the formula: $\mathrm{e}^{-\rho t}$ is a method of compound discount called discount factor, and play a role of convergent factor; $\rho \succ 0$ means that discount rate or the rate of time preference is subjective.

\section{Model Solution}

\subsection{The Establishment of Hamilton Function}

The important research results of modern economic growth theories show the growth rates of all the per cap- ita variables are constants in the process of long-term growth [11]. Therefore, the dynamic optimization problem of Formula (2) can be well solved by means of Pontryagin maximum principle, so that we can work out the first order condition for the optimal economic and social growth. We set up current-value Hamiltonian function to solve the optimization problem, so as to avoid the conflict between the function and human capital symbol $H$, we purposely replace current-value Hamiltonian function $H$ in common sense by $J$, moreover, the function is as follows:

$$
\begin{aligned}
J= & U(C, S, P)+\lambda_{1}(Y-C-\phi K) \\
& +\lambda_{2}[\pi(1-u) H N-\sigma N]+\lambda_{3}(\eta S-E) \\
& +\lambda_{4}\left(\phi^{-b} K^{-b} Y N^{-a}-\varpi P\right) \\
= & \left(\frac{C^{1-\varepsilon}-1}{1-\varepsilon}+\frac{S^{1-\omega}-1}{1-\omega}+\frac{P^{1+\varphi}-1}{1+\varphi}\right) \\
& +\lambda_{1}(Y-C-\phi K) \\
& +\lambda_{2}[\pi(1-u) H N-\sigma N] \\
& +\lambda_{3}(\eta S-E)+\lambda_{4}\left(\phi^{-b} K^{-b} Y N^{-a}-\varpi P\right)
\end{aligned}
$$

In the formula: $C, E, u, \phi$ are middle control variables of each state variable; $K, N, S, P$ are state variables; $\lambda_{1}, \lambda_{2}, \lambda_{3}, \lambda_{4}$ are the shadow prices of each state variable. The first order condition is:

$$
\begin{aligned}
\frac{\partial J}{\partial C}=0 & \Rightarrow \lambda_{1}=C^{-\varepsilon} \\
\frac{\partial J}{\partial u}=0 & \Rightarrow \lambda_{1} \frac{\partial Y}{\partial u}-\lambda_{2} \pi H N \\
& +\lambda_{4} \phi^{-b} K^{-b} N^{-a} \frac{\partial Y}{\partial u}=0 \\
& \Rightarrow \lambda_{2} \pi H N=\left(\lambda_{1}+\lambda_{4} \phi^{-b} K^{-b} N^{-a}\right) a \frac{Y}{u} \\
\frac{\partial J}{\partial E}=0 & \Rightarrow \lambda_{1} \frac{\partial Y}{\partial E}-\lambda_{3}+\lambda_{4} \phi^{-b} K^{-b} N^{-a} \frac{\partial Y}{\partial E}=0 \\
& \Rightarrow \lambda_{3}=\left(\lambda_{1}+\lambda_{4} \phi^{-b} K^{-b} N^{-a}\right) \beta \frac{Y}{E} \\
\frac{\partial J}{\partial \phi}=0 & \Rightarrow-\lambda_{1} K-\lambda_{4} b \frac{K^{-b} Y N^{-a}}{\phi^{1+b}}=0 \\
& \Rightarrow \lambda_{1} K=-\lambda_{4} b \frac{K^{-b} Y N^{-a}}{\phi^{1+b}}
\end{aligned}
$$

The four Euler equations are as follows: 


$$
\begin{aligned}
& \dot{\lambda}_{1}=\rho \lambda_{1}-\frac{\partial J}{\partial K}=\rho \lambda_{1}-(1-\alpha-\beta) \lambda_{1} \frac{Y}{K} \\
& +\lambda_{1} \phi-\lambda_{4} \frac{Y \phi^{-b} N^{-a}}{K^{1+b}}(1-\alpha-\beta-b) \\
& \dot{\lambda}_{2}=\rho \lambda_{2}-\frac{\partial J}{\partial N}=\rho \lambda_{2}-\lambda_{1}(\alpha+\beta) \frac{Y}{N} \\
& -\lambda_{2}[\pi(1-u) H-\sigma]-\lambda_{4} \frac{Y \phi^{-b} K^{-b}}{N^{1+a}}[(\alpha+\beta)-b] \\
& \dot{\lambda}_{3}=\rho \lambda_{3}-\frac{\partial J}{\partial S}=\rho \lambda_{s}-S^{-\omega}-\eta \lambda_{3} \\
& \dot{\lambda}_{4}=\rho \lambda_{4}-\frac{\partial J}{\partial P}=\rho \lambda_{4}+P^{\varphi} \\
& +\theta \frac{Y}{P}\left(\lambda_{1}+\lambda_{4} \phi^{-b} K^{-b} N^{-a}\right)+\lambda_{4} \varpi
\end{aligned}
$$

\subsection{The Solution of the Growth Rate of Each Variable in the Steady-State Growth}

According to the dynamic optimization theory, the growth rate of each economic variable shows the characteristics of balanced growth in the optimal economic and social growth path. Assume the growth rates of each variable are $g$, that is,

$g_{C}=\frac{\dot{C}}{C}, g_{K}=\frac{\dot{K}}{K}, g_{N}=\frac{\dot{N}}{N}, g_{\lambda_{1}}=\frac{\dot{\lambda}_{1}}{\lambda_{1}}, \cdots$. Obviously, we can obtain the growth rate of each variable in the steadystate economic growth, and then analyze how each parameter influences the growth rates and what kind of economic policies can be put in to achieve the sustainable growth of energy, environment and economic. The growth rates obtained are as follows: Equations (6)-(8).

$$
\begin{aligned}
g_{u}= & g_{\phi}=0, \\
g_{Y}= & g_{K}=g_{C}=\frac{a(1+\varphi)[\pi(1-u) H-\sigma]}{\varphi(1-b)+(\varepsilon-b)} \\
g_{P}= & (1-b) g_{Y}-a g_{N} \\
= & \frac{a(1+\varphi)(1-b)[\pi(1-u) H-\sigma]}{\varphi(1-b)+(\varepsilon-b)} \\
& -a[\pi(1-u) H-\sigma]
\end{aligned}
$$

\section{Results Analysis}

\subsection{The Essential Condition for Sustainable Economic Growth}

Under the dual constraints of energy and environment, sustainable economic growth requires at least three essential conditions:

1) The economic growth rate is positive, that is,

$g_{Y}=\frac{a(1+\varphi)[\pi(1-u) H-\sigma]}{\varphi(1-b)+(\varepsilon-b)} \succ 0$, thus, see Equation (9).

It can be seen that, under the circumstance of the given human capital $H$, knowledge production rate $\pi(1-u) H$, the clean index of energy technology $a$, the environmental protection investment efficiency $b$ and the productivity rate of design $\pi$ have a positive effect on the economic growth rate $g_{Y}$, while the aging rate of knowledge $\sigma$ and the distribution proportion of human capital between finished department and $\mathrm{R} \& \mathrm{D}$ department $u$ have a negative effect on it.

2) The irreversibility of ecosystem decides ecosystem has a threshold $P^{\max }$. Ecosystem has self-purification and recovery capacity within threshold, once exceed, ecosystem self-purification and absorptive capacity will shrink or be lost even permanently. So $g_{P} \prec 0 \Rightarrow(1-\varepsilon) \prec 0 \Rightarrow \varepsilon \succ 1$, that is sustainable economic growth requires the growth rate of pollutants is negative in the steady-state growth. Based on foregoing analysis, $\varepsilon$ is the reciprocal of intertemporal substitution elasticity for consumption, the bigger $\varepsilon$ is, the faster the diminishing speed of marginal utility for consumption is, the weaker the preference of household consumption is, the weaker the consumer desire is. In the condition for sustainable economic growth, only $\varepsilon \succ 1$ can guarantee the growth rate of pollutants is negative, indicating improving the decline of environmental quality caused by pollution emissions will increase emission charges and obviously produce the supplanting effect on consumption.

3) To ensure energy stock can meet energy demand, the growth rate of energy consumption can't exceed that of energy stock, that is, $g_{E} \leq g_{S}$; meanwhile, as sustainable economic growth relays on energy, the growth rate of energy consumption should not exceed that of economic, otherwise it will eventually make energy dry up, even if technique can make energy stock maintain a certain growth rate. Therefore, in the steady-state growth,

$$
g_{Y} \geq g_{E}=g_{S} \Rightarrow \varepsilon \prec \frac{(a+b)(1+\varphi)}{\varphi}
$$

In conclusion, in the steady-state it is formulas:

$u \prec 1-\frac{\sigma}{\pi H}, \quad b \succ \frac{\varphi}{1+\varphi}, \frac{(a+b)(1+\varphi)}{\varphi} \succ \varepsilon \succ 1$ that together determine the conditions for sustainable economic growth.

$$
g_{E}=g_{S}=\frac{[\pi(1-u) H-\sigma]}{\beta[\varphi(1-b)+(\varepsilon-b)]} \cdot\{[(a+b)(1+\varphi)-(\varepsilon+\varphi)](\alpha+\beta)+a \theta(1-\varepsilon)\}
$$




$$
\left\{\begin{array}{l}
\pi(1-u) H-\sigma \succ 0 \Rightarrow u \prec 1-\frac{\sigma}{\pi H} \\
\varphi(1-b)+(\varepsilon-b) \succ 0 \Rightarrow\left\{\begin{array} { l } 
{ \varepsilon \succ b + b \varphi - \varphi } \\
{ \varepsilon \succ 0 }
\end{array} \Rightarrow \left\{\begin{array}{l}
\varepsilon \succ b+b \varphi-\varphi \\
b \succ \frac{\varphi}{1+\varphi}
\end{array}\right.\right.
\end{array}\right.
$$

\subsection{Pollution Control and Sustainable Economic Growth}

By Formulae (6) and (7) we can obtain the relationship between environmental pollution and economic growth is:

$$
g_{Y}=\frac{(1+\varphi)}{(1-\varepsilon)} g_{P} .
$$

Only $\varepsilon \succ 1$ can guarantee that the growth rate of pollutants is negative, indicating the environmental pollution has a huge effect on sustainable economic growth. Since pollutants are produced and have a negative effect on economic along with the process of sustainable economic growth, besides owing to the restriction of ecosystem threshold, the growth rate of pollutants must be negative in the steady-state. Moreover, the existence of environmental pollution externality will deteriorate environmental quality, thus produce the supplanting effect on consumption and influence total social welfare utility. Hence, we must strengthen pollution control. In the light of foregoing analysis, only when the proportion of investment in pollution control in capital stock remains unchanged, can we achieve sustainable growth of energy, environment and economy. Apparently, once investment in pollution control is too low, certainly it will destroy the steady-state of equilibrium growth and cause massive increases of pollution stock $\mathrm{P}$ in the environment, when the pollution stock exceed the threshold of environmental capacity, necessarily it will induce environmental crisis and result in more economic losses.

Environmental protection has a close relation with sustainable economic growth, and the key to solve environmental problems is adding investment in environmental protection and enhancing its efficiency. Since China's economic is always developed in an extensive growth path of high input, consumption, growth rate but low environmental standards, people always hold the principle of growth priority in development conception, they believe increasing investment in environmental protection will influence economic growth. Neither local government nor enterprises pay attention to environmental protection, which leads to a seriously low proportion of environmental protection investment. In recent years, China's investment in pollution control, improving environmental quality and ecological protection has achieved good results. However, the existing investment in environmental protection still works under the system of planned economy, which results in many problems. To change the status quo, we should set up a high level of environmental awareness firstly, form effective environmental protection policies, ensure investment environmental protection at the institutional level, and actively promote cleaner production methods finally.

\subsection{Energy Consumption and Sustainable Economic Growth}

Leaving the impact of renewable energy on the energy stock out of consideration is not only unscientific but also inconsistent with the fact that the world is vigorously developing renewable energy. As previously noted, in terms of the internal logic of endogenous growth model, it is endogenous technology that solves the scale descending of other factors to make sustainable economic growth possible.

Sustainable development theory shows energy use must follow the minimum safety standards: the speed of social use of renewable energy can't exceed its update speed; the speed of social use of non-renewable energy can't exceed the development rate of sustainable nonrenewable energy of its substitute $[14,15]$. In terms of the world current situation, consumption of non-renewable resources occupies a predominant proportion in energy consumption, economic development excessively depends on oil, coal and other exhaustible energy, thus it is difficult to guarantee minimum safety standards. Therefore, before the proportion of renewable resources reaches a certain number, energy use must emphasize both resources development and energy saving policies.

\subsection{Human Capital Accumulation, Technological Innovation and Sustainable Economic Growth}

Due to Formula (6), it can be seen that when the other conditions remain unchanged in the steady-state, economic growth rate and human capital change in the same direction. Therefore, increasing human capital investment can improve economic growth rate in the steadystate. Further study shows that economic growth rate changes inversely with the distribution ratio of human capital in finished department while it changes in the same direction with the distribution ratio in $\mathrm{R} \& \mathrm{D}$ de- 
partment. So it is human capital investment in R \& D department that really impacts economic growth rate, we can obtain sustainable economic growth by increasing total investment in human capital or the distribution ratio of human capital in R \& D department.

The conclusion shows the importance of human capital in R \& D department to economic growth. Actually, it is possible to achieve sustainable economic growth, precisely because human capital in R \& D department can produce more knowledge and technology products, whose spillover changes the phenomenon of the scale benefit descending of other production factors, that is, technology and knowledge are the final "source" of economic growth. It is the foundations for endogenous technological change model as well.

\section{Conclusions}

On the basis of previous research, this paper introduces energy and environment into both production and utility function, develops a five-sector endogenous technological growth model based on the expansion of product categories, completely describes the internal mechanism of sustainable energy use, pollution control, R \& D innovation and sustainable economic growth, gets the following main conclusions:

1) Under the dual constraints of energy and environment, sustainable economic growth can be achieved, the conditions for sustainable economic growth are decided together by formulas:

$$
u \prec 1-\frac{\sigma}{\pi H}, b \succ \frac{\varphi}{1+\varphi}, \frac{(a+b)(1+\varphi)}{\varphi} \succ \varepsilon \succ 1 .
$$

Under these conditions, endogenous technology can overcome the constraints of energy and environment to make sustainable economic growth possible. The basic conclusions of the model show the pivotal role of R \& D and human capital investment in sustainable economic growth under the dual constraints of energy and environment: on one hand, human capital accumulation and technological progress are the power and source of long-term economic growth; on the other hand, as the technology producing human capital and technical knowledge is more efficient and cleaner than technology producing material capital, thus under the constraints of energy consumption, environmental pollution, human capital development and technological innovation become important means to maintain sustainable economic growth.

2) Under the circumstance of the given human capital $H$, knowledge production rate $\pi(1-u) H$, the clean index of energy technology $a$, the environmental protecttion investment efficiency $b$ and the productivity rate of design $\pi$ have a positive effect on economic growth rate
$g_{Y}$, while the aging rate of knowledge $\sigma$ and the distribution proportion of human capital between finished department and $\mathrm{R} \& \mathrm{D}$ department $u$ have a negative effect on it. The conclusion reminds people as a social planner government should do something about human capital development, R \& D, environmental protection and other departments: 1) government intervention may influence the department of human capital development and the distribution ratio of human capital in production department, enhancing the human capital levels and properly reducing the distribution ratio of human capital in production department can improve long-term economic growth rate; 2) government can directly go in for $\mathrm{R} \& \mathrm{D}$ activities or encourage private enterprises to increase R \& D investment by financial subsidies, tax incentives and supporting venture investment market so as to improve long-term economic growth rate; 3) government can advocate the development and use of clean energy to enhance the clean index of energy and improve the efficiency of investment in environmental protection in order to improve the long-term economic growth rate.

3) In the steady-state only when the proportion of investment in pollution control in capital sock remains unchanged and pollution control efficiency is constrained by minimum, can we achieve the sustainable growth of energy, environment and economic. Apparently, once investment and efficiency of environmental pollution control is too low, it will destroy the steady-state of equilibrium growth certainly and cause massive increases of pollution stock in the environment, when the pollution stock exceed the threshold of environmental capacity, necessarily it will induce environmental crisis and result in more economic losses. Nowadays, China has already become one of the major emitters of pollutants in the world, we should set up a high level of environmental awareness firstly, insure the level of environmental protection investment from the angle of institutions and improve the efficiency of investment in environmental protection.

\section{Policy Implications}

After 30 years of rapid development, in 2010 China's GDP exceeded Japan so that China became the second largest economy in the world, however, China paid a heavy cost of energy and environment for it: energy consumption was 3.25 billion tons of standard coal and the second largest in the world! Among it the proportion of unclean coal was $70 \%$ high, which brought about serious environmental pollution. The extensive growth paying the price of sacrificing energy and environment is not sustainable, government proposed the strategic goal of building a "two-oriented society" timely, and policy implications of this paper are as follows: 
1) Government should pay more attention to education and invest more in it as well as support scientific and technological innovation and application in many ways. It pointed out earlier that as a social planner government should do something about human capital development, $\mathrm{R} \& \mathrm{D}$, environmental protection and other departments, besides, government can also make a difference on education, since government intervention may influence the level of human capital. As education is one of the main ways of investment in human capital, the level of human capital is closely related with the whole process of education. If government intervention could improve a country's education investment, thereby the level of human capital will be enhanced, thus the long-term economic growth rate will be improved. In 2008 China's average education attainment is only 8.45 years, has not yet reached the level of 9-year compulsory education formulated by the state, so there is a big room to improve.

2) Government should increase investment in environmental protection and improve its efficiency. For a long time, the principal part of China's investment in environmental protection is single, thus government investment is the dominant, while private investment is relatively less. Owing to the lack of investment in environmental protection, environmental protection facilities can't be maintained and updated, which leads to the difficulty for facilities to achieve the expected result of design. Therefore, government should institutionally strengthen the efforts to control the existence of external diseconomy and simultaneously cultivate diverse princepal part of investment in environmental protection to solve the issues that investment in environmental is lack and its efficiency is too low, so that the long-term economic growth rate is enhanced.

3) Government should improve energy efficiency, vigorously adjust energy consumption structure and encourage the development of renewable and clean energy. Studies have shown that the most important factors that affect pollution emissions are energy consumption structure and energy efficiency [16,17]. Over the years, the coal-dominated energy consumption structure has caused a greater environmental pressure, in line with forecast of China's energy consumption structure from Bo-qiang Lin, Zhu-jun Jiang [18], under the constraints of energy planning objectives, in 2040 the proportion of China's coal consumption in energy consumption will still be up to $56.11 \%$ ! Therefore, it is extremely difficult for China to reduce pollution emissions through improving energy consumption structure, only relying on the improvement of energy efficiency is the first choice! In addition, the total amount of non-renewable energy can be increased in the short term with the help of the exploration and utilization technology, but its limited reserves determines that its natural growth rate will gradually converge to zero as time goes on, while the renewable energy growth is not limited by reserves, so the only way leading to sustainable development of energy and economy is developing renewable. At present, China's utilization proportion of clean and high quality non-fossil fuel mainly including hydropower, nuclear power and wind power is no more than $8 \%$. As a result, government must increase investment in renewable energy technologies and Industriously develop renewable energy to replace exhaustible fossil energy. Meanwhile, government should support the development and utilization of biomass energy mainly using agriculture and forestry residuals, livestock manure and municipal waste, increase investment in clean fuel mainly including hydropower, nuclear power and wind power to reduce the impact of pollution emissions on environment and enhance the clean index of energy, thereby the long-term economic growth rate will be improved.

Government should change the existing cadre evaluation system and transform its view of performance. In the performance evaluation of local government officials, energy conservation and emission reduction have become a real indicator, whereas indicators of economic development still occupy a more important position. Government's view of performance aimed to GDP results in the fact that many local government officials only put economic development first and ignore the importance of energy conservation and emission reduction. Therefore, government should increase the weight of energy conservation and emission reduction in the performance evaluation for government officials, one-vote negation system can be implemented when necessary.

\section{REFERENCES}

[1] P. Romer, "Increasing Returns and Long-Run Growth," Journal of Political Economy, Vol. 94, No. 5, 1986, pp. 1002-1037. doi: $10.1086 / 261420$

[2] P. Romer, "Endogenous Techonlogical Change," Journal of Political Economy, Vol. 98, No. 5, 1990, pp. 71-102. doi: $10.1086 / 261725$

[3] R. Lucas, "On the Mechanics of Economic Development," Journal of Monetary Economics, Vol. 22, No. 1, 1988, pp. 3-42. doi:10.1016/0304-3932(88)90168-7

[4] S.-J. Peng, "Natural Resources Depletion and Sustainable Economic Growth: Based on the Analysis of Four-Sector Endogenous Economic Growth Model," Journal of Industrial Engineering and Engineering Management, Vol. 21, No. 4, 2007, pp. 119-124.

[5] S.-C. Xu, Z.-X. He and X.-P. Wei, "Sustainable Economic Growth Model in the Framework of Resource Consumption, Technological Progress and Human Capital Accumulation," Journal of Harbin Institute of Technology: Social Sciences Edition, Vol. 10, No. 4, 2008, pp. 83-88. 
[6] S.-B. Li and D.-T. Zhao, "Endogenous Growth Model of Sustainable Economic Development under the Constraints of Environmental Polllution," Forecasting, Vol. 27, No. 1, 2008, pp. 72-76.

[7] J. Huang, "Environmental Pollution, Human Capital and Endogenous Economic Growth: A Simple Model," South China Journal of Economics, Vol. 4, 2009, pp. 3-11.

[8] B. Zhang and H. Zuo, "Energy Sustainable Use, Environmental Management and Endogenous Economic Growth," China Population Resources and Environment, Vol. 17, No. 5, 2007, pp. 27-32.

[9] S.-C. Xu, Z.-X. He and X.-P. Wei, "The Optimal Path of Sustainable Economic Growth under the Constraints of Resource Consumption and Pollution Control," Journal of Management Sciences in China, Vol. 13, No. 1, 2010, pp. 20-30.

[10] S. Karl, "Toward a Theory of Inventive Activity and Capital Accumulation," American Economic Revie, Vol. 56, No. 5, 1966, pp. 62-68.

[11] R. Barro and X. Sala-I-Martin, "Economic Growth (Second Edition)," The MIT Press, London, 2004, pp. 319330.

[12] J.-K. Li, “The Research of Energy Constraint and China's
Economic Growth: Theoretical and Empirical Rerearch," China Logistics Publishing House, Beijing, 2009, p. 179.

[13] N. L. Stokey, "Are There Limits to Growth?" International Economic Review, Vol. 39, No. 1, 1998, pp. 1-31. doi: $10.2307 / 2527228$

[14] H. E. Daly and J. B. Cobb, "For the Common Goods: Redirecting the Economy toward Community, the Environment and a Sustainable Future," Beacon Press, Boston, 1989, pp. 571-576.

[15] N. L. Stokey, “Are There Limits to Growth?" International Economic Review, Vol. 39, No. 1, 1998, pp. 1-31. doi: $10.2307 / 2527228$

[16] W.-P. Yang, "Analysis of Dynamic Comprehensive Evaluation and Impact Factors of China's Provincial-Level Environmental Quality," Economic Management Journal, Vol. 8, 2010, pp. 159-165.

[17] G.-Z. Li, J.-R. Jiang and C.-Y. Zhou, "Analysis of Relationship between Total Factor Energy Efficiency and Environmental Pollution," China Population Resources and Environment, Vol. 20, No. 4, 2010, pp. 50-56.

[18] B.-Q. Lin and Z.-J. Jiang, "Forecast and Factors of China's Carbon Kuznets Curve," Management Word, Vol. 4, 2009, pp. 27-30. 